\title{
Homograft aortic root with prosthetic extension as a treatment for aneurysm of the proximal aorta in elderly patients
}

M. E. Lewis, FRCS, T. J. Jones, FRCS, A. M. Ranasinghe, MRCS, J. R. Lewis, MB, ChB, and

R. S. Bonser, FRCP, FRCS, Birmingham, United Kingdom

From the Department of Cardiothoracic Surgery, Queen Elizabeth Hospital, Birmingham, United Kingdom.

Received for publication Sept 25, 2001; accepted for publication Oct 23, 2001.

Address for reprints: R. S. Bonser, FRCP, FRCS, Cardiothoracic Surgical Unit, Queen Elizabeth Hospital, University Hospital NHS Trust, Edgbaston, Birmingham B15 2TH, United Kingdom (E-mail: r.s.bonser@bham.ac.uk).

J Thorac Cardiovasc Surg 2002;123:573-5

Copyright $\odot 2002$ by The American Association for Thoracic Surgery $0022-5223 / 2002 \$ 35.00+0 \quad \mathbf{1 2 / 5 4 / 1 2 1 2 8 9}$

doi: $10.1067 / \mathrm{mtc} .2002 .121289$

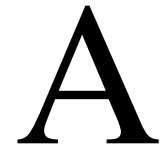

ortic root dilatation is the commonest cause of severe aortic regurgitation and its incidence increases with age. ${ }^{1}$ The need for surgery is determined both by the severity of aortic regurgitation and by the extent of aortic dilatation. Aortic valve replacement is offered to those patients with symptomatic severe aortic regurgitation with or without compromise of left ventricular dynamics. However, in the context of the dilated aorta, isolated aortic valve replacement is associated with a late incidence of aortic rupture. ${ }^{2}$ Even if an aortoplasty procedure is performed at the time of valve replacement, aneurysm recurrence rates are high. Therefore, dilatation of the aortic root to greater than $40 \mathrm{~mm}$ in association with aortic regurgitation is usually considered an indication for root replacement. ${ }^{3}$ 


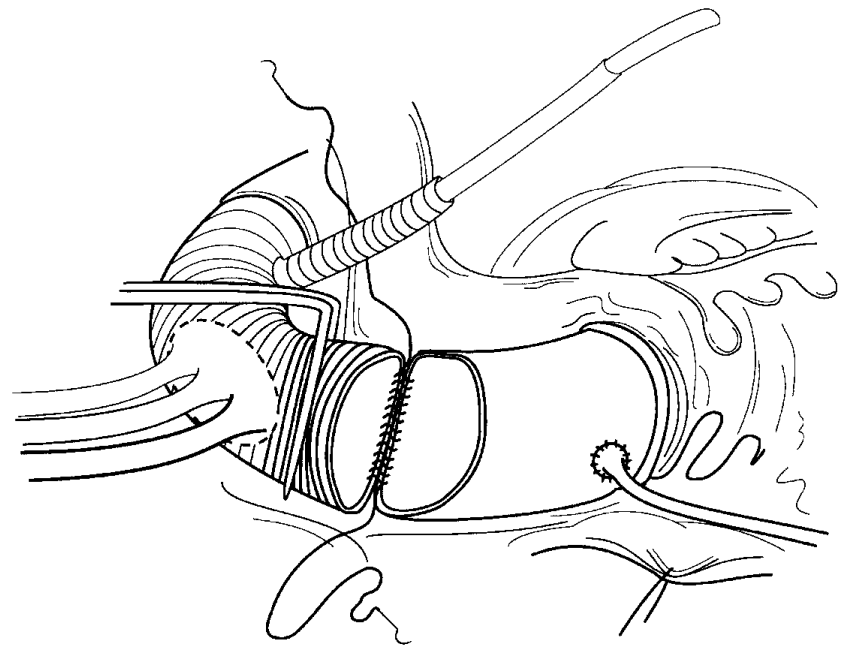

Figure 1. Operative technique demonstrating graft-homograft anastomosis. Note Carrell patch and perfusion through side arm of the Ante-Flo graft.

The older patient with this condition provides a therapeutic challenge. Good results for aortic prosthetic replacement or valvesparing repair in younger patients have been demonstrated. ${ }^{4}$ However, the friable nature of the tissues in elderly patients makes these surgical options less attractive in this group.

Recent work has shown the excellent long-term results that can be achieved with homograft replacement of the aortic valve in elderly patients with isolated valve disease. ${ }^{5}$ It would appear that the rate of freedom from tissue failure increases with increased age, which in addition to the excellent hemostatic and handling properties of these grafts makes them particularly suitable for use in the mature patient. In addition, the desire to avoid anticoagulation in the elderly patient increases the need for a biologic valve substitute.

Extrapolation of these data led us to consider the use of a combination homograft prosthetic replacement strategy in patients with aortic regurgitation and aneurysm of the proximal aorta.

\section{Patients and Methods}

Between January 1995 and March 2001, 29 patients (7 male, mean age 74 years; range 58-85 years) underwent composite replacement of the aortic root (homograft) and ascending aorta/arch (polyester graft [Gelweave; Sulzer Vascutek Ltd, Renfrewshire, Scotland]). Aortic arch replacement was performed in 22 patients and open distal anastomosis in 7 patients.

After induction of anesthesia and insertion of a monitoring line, median sternotomy was performed. Cardiopulmonary bypass was initiated with right atrial drainage and either arch or femoral arterial return. After a period of hypothermic circulatory arrest, the arterial return was transferred to the reconstructed aorta via the side arm of the prosthetic graft (Sulzer Vascutek Gelweave Ante-Flo).

After median sternotomy, the pericardium was opened and purse-string sutures were placed in the right atrium and ascending aorta or femoral artery. Cannulation was performed and cardiopul-

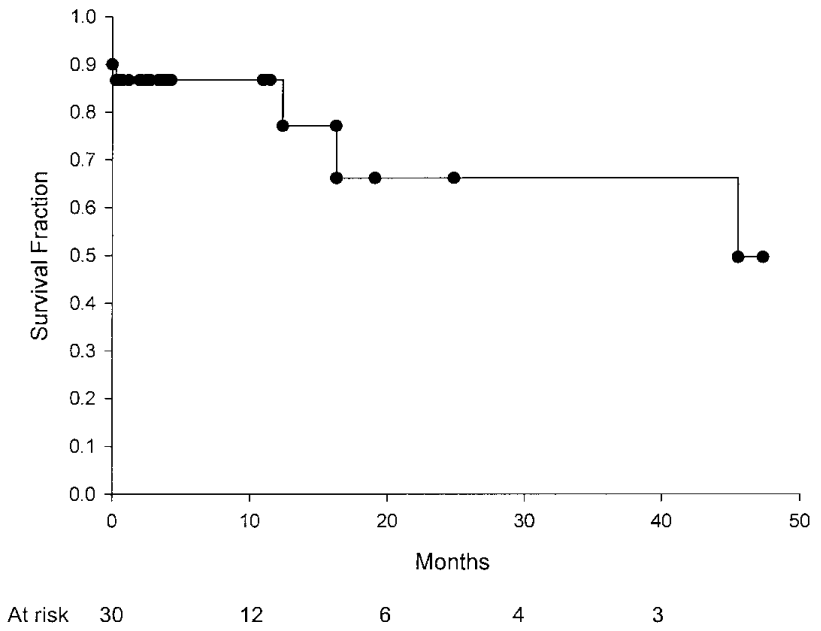

Figure 2. Kaplan-Meier curve of survival in months after surgery.

monary bypass was commenced. The patients were routinely cooled to $15^{\circ} \mathrm{C}$ with alpha-stat $\mathrm{pH}$ control. Once bypass was established, the aorta was mobilized. If arch repair was to be performed, the recurrent laryngeal nerve was identified and protected and the ligamentum arteriosum divided. The ascending aorta was crossclamped, the heart electrically fibrillated, the aorta opened, and cold blood cardioplegic solution was instilled directly into the coronary ostia. The aortic valve was excised and the native coronary ostia were mobilized on buttons of the aortic wall. Homograft root replacement was undertaken with simple interrupted 4-0 polypropylene sutures to the anulus. The coronary buttons were reimplanted with 5-0 continuous polypropylene. Suture-line integrity was assessed under direct vision during delivery of a further dose of cardioplegic solution. Attention was next directed to the remaining aorta. At $15^{\circ} \mathrm{C}$, the circulation was arrested, the crossclamp removed, and the aneurysmal aorta excised. If the aneurysm extended into the aortic arch, then a Carrel patch was fashioned from the epiaortic vessels. The distal anastomosis was performed under direct vision. If arch replacement was undertaken, a section of graft material was excised opposite the Carrel patch, anastomosis was performed, and the arterial return was transferred to the perfusion limb of the graft (Gelweave Ante-Flo, Sulzer Vascutek) after rigorous arch air drill. The graft-homograft anastomosis was then fashioned. All graft anastomoses were formed with buttressed continuous 4-0 polypropylene suture. Hemostasis was checked and fibrin glue applied to the proximal anastomoses. After air drill, rewarming, and weaning from bypass, hemostasis was secured and the chest closed. Operative technique is further detailed in Figure 1.

\section{Results}

Cardiopulmonary bypass and hypothermic circulatory arrest times were a mean of $188 \pm 38$ and $35 \pm 13$ minutes, respectively, with a cardiac ischemic period of $139 \pm 19$ minutes. There were 3 inhospital deaths, 2 from low cardiac output syndrome and 1 from pneumonia (overall survival to discharge 89\%). The median inten- 
sive treatment unit and cardiac hospital stays in survivors were 2 days (range 1-33 days) and 12 days (range 5-47 days), respectively. Two patients required temporary tracheostomy. Follow-up is $100 \%$, and at a mean of 20 months there have been 3 late deaths at 13,37 , and 47 months (rupture of a descending aortic aneurysm, bronchopneumonia, and bronchopneumonia, respectively). Median survival was 45.5 months and Kaplan-Meier data are shown in Figure 2. All survivors remain in New York Heart Association class I or II, requiring only aspirin and antihypertensive medication. Serial prospective echocardiograms show no patient with greater than trivial aortic regurgitation, and all computed tomographic scanning surveillance is satisfactory. There have been no episodes of thromboembolism.

\section{Discussion}

The use of a composite homograft root with a prosthetic extension in elderly patients with aortic aneurysm and proximal aortic disease has several potential advantages, including (1) use of a valve prosthesis that has improving results with advanced age, (2) the ability to deal fully with the arch disease, and (3) the avoidance of anticoagulation. This novel technique can be used to achieve good results in this group of elderly patients. Although early mortality was higher than in published series of homograft replacement alone,${ }^{5}$ the more extensive nature of this operation and the more elderly population still allow us to conclude that this is a valuable operative strategy in this group.

There have been no midterm valve failures. This finding is in keeping with that of Lund and associates, ${ }^{5}$ who demonstrated an improved allograft survival in the elderly patient. All patients in this series have excellent neoaortic valve function on transthoracic echocardiography. We believe that this composite approach may be an optimal strategy for aneurysm of the proximal aorta with aortic regurgitation in elderly patients.

We are indebted to the anesthetic, technical, and nursing staffs of the cardiothoracic surgical unit, who have supported this program.

\section{References}

1. Singh JP, Evans JC, Levy D, Larson MG, Freed LA, Fuller DL, et al. Prevalence and clinical determinants of mitral, tricuspid, and aortic regurgitation (the Framingham Heart Study) Am J Cardiol. 1999;83:897-902 (published erratum appears in Am J Cardiol. 1999;84:1143).

2. McDonald ML, Smedira NG, Blackstone EH, Grimm RA, Lytle BW, Cosgrove DM. Reduced survival in women after valve surgery for aortic regurgitation: effect of aortic enlargement and late aortic rupture. J Thorac Cardiovasc Surg. 2000;119:1205-12.

3. Natsuaki M, Itoh T, Rikitake K, Okazaki Y, Naitoh K. Aortic complications after aortic valve replacement in patients with dilated ascending aorta and aortic regurgitation. J Heart Valve Dis. 1998;7:504-9.

4. Yacoub MH, Gehle P, Chandrasekaran V, Birks EJ, Child A, RadleySmith R. Late results of a valve-preserving operation in patients with aneurysms of the ascending aorta and root. J Thorac Cardiovasc Surg. 1998;115:1080-90.

5. Lund O, Chandrasekaran V, Grocott-Mason R, Elwidaa H, Mazhar R, Khaghani A, et al. Primary aortic valve replacement with allografts over twenty-five years: valve-related and procedure-related determinants of outcome. J Thorac Cardiovasc Surg. 1999;117:77-90. 